\title{
LQG Control Strategy for Enhancing Ride and Safety Performance of Electric Vehicle Driven by In-Wheel Motors
}

\author{
LiQiang Jin, Yue Liu and JianHua Li*
}

State Key Laboratory of Automotive Simulation and Control, Jilin University, Changchun 130022, China

\begin{abstract}
In this paper, a method for reducing unspring mass as well as improving safety and ride properties of vehicles driven by in-wheel motors will be provided. To begin with, the advantages of vehicles armed with in-wheel motors will be described, after which some drawbacks of this idea will be studied. Then, to getting a better analysis, quarter car model will be studied in frequency domain. Gain of body acceleration and wheel dynamic load, which can be equal to ride property and safety performance respectively, will be compared. Finally, an idea that makes the drive motor suspend will be proposed for enhancing the two properties and then a LQG controller will be provided for further optimization. Through the comparison in time domain and frequency domain, one can come to a conclusion that vehicles driven by suspended motors not only simplified the structures but also can be used as an absorber for vibration reduction.
\end{abstract}

Keywords: Vehicle engineering, in-wheel motor drive, ride property and safety, suspend, LQG controller, vibration reduce.

\section{INTRODUCTION}

Scarcity of fuel has brought in great concerns to us today. Gasoline, which has been the major power source of classical vehicles for decades, got its price soaring up year by year, which results in an unstoppable trend of conventional cars being replaced by vehicles powered not by gasoline but other new energy, such as Electric Vehicles. However, the cost of devices of Electric Vehicles is always considerable. In-wheel motor Electric Vehicle present us a practical way of designing an Electric Vehicle with its cost reduced and at the same time performance improved compared to traditional vehicles, also this structure is likely to be the ultimate form of EV design $[1,2]$. Vehicles manufactured in this way need not to be armed with complex gearbox, heavy transmission shaft etc., the drive torque can be controlled directly by the motor. The performance of inwheel motor Electric Vehicle is likely to perform better compared with that of classical vehicles once a good control system is invented [3-5]. The advantages of Electric Vehicles driven by in-wheel motors(MEV) did not stop there. Motor could recover energy from Kinetic Energy of Electric Vehicle during braking, which is remarkably valuable for future use [6]. Motor can unleash torque very quickly and accurately. The value of torque with this feature, do be demonstrated by some researchers [7]. Motorized Electric Vehicles can assist steering by differentiating torque to the left and right wheel motors [8], which in turn lower the hand toque burden without additional devices(like EPS). The basic scheme of MEV can be simplified as Fig. (1). The driver motion signal, generated by the driver, is converted to the reasonable torque of the in-wheel motors that attached to

*Address correspondence to this author at the State Key Laboratory of Automotive Simulation and Control, Jilin University, Changchun 130022, China; Tel: +86-18686538629; E-mail: lijianhuajlu@163.com each wheel by the motor controller through the electronic control unit(ECU).

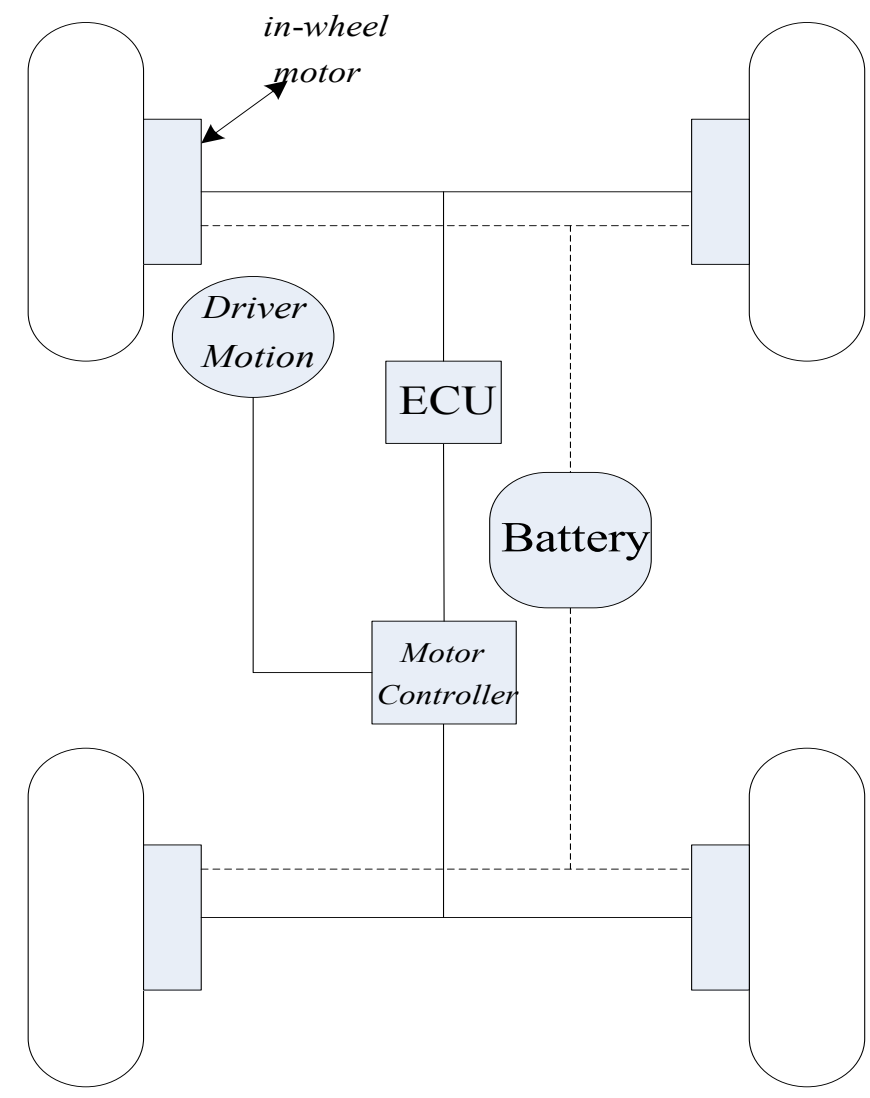

Fig. (1). structure of motorized electric vehicle.

It is, however, the unspring mass of this kind of structure is added because of the motor attached to the wheels. Seen from Fig. (2), which is a test of in-wheel motor that used in 
Bora(a car from Volkswagen). The mass of this motor nearly the same as the wheel.

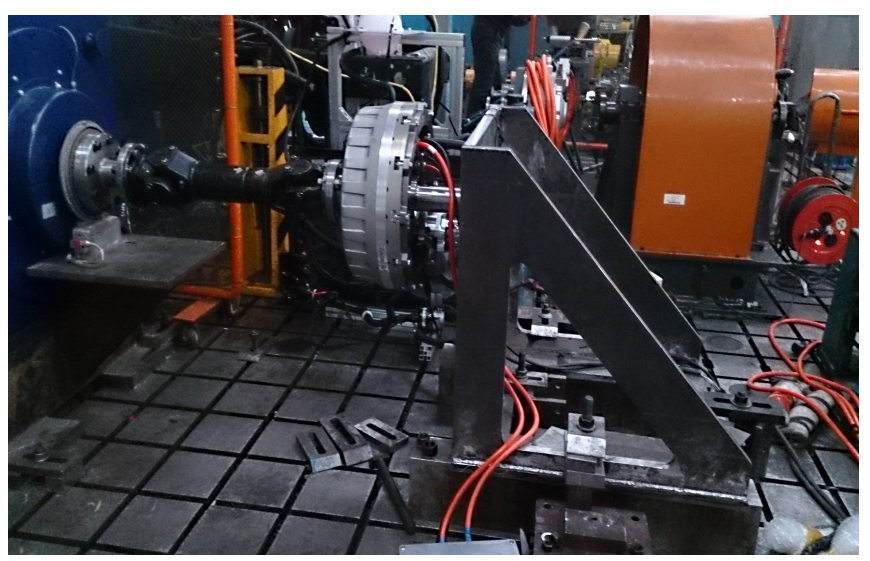

Fig. (2). Tests of motor performance in laboratory.

The safety and ride property will be deteriorated based on that reason. To solving the problem, a method that make the motor suspend is researched by LiQiang Jin [9], yet the study did not give out a idea how to suspend, besides no appropriate control law was provided in terms of the ride and safety properties. Researches on this theme are also rarely. In this study, vehicle vibration properties in time domain and frequency domain will be analyzed, after which a layout method will be provided to solve the problem of unspring mass increasing, then an active LQG control strategy will be proposed for a better improvement. From the comparison of simulation results, the solution provided in this paper is confirmed to have the ability to enhance ride property and safety of vehicles driven by in-wheel motors.

\section{STRUCTURE OF VEHICLES DRIVEN BY IN- WHEEL MOTORS AND DRAWBACK ANALYSIS}

To have a better understanding of the structure, a simplified vibration model will be provided as Fig. (3). Fig. (3a) shows the vibration model of classical car without in- wheel motors, while Fig. (3b) shows the simplify of scheme in Fig. (1). The model is widely used in analyzing vehicle vibration problems. The dynamic equations of the vehicle suspension system will derived though Newton law as:

$$
\left\{\begin{array}{l}
m_{2} \ddot{s_{2}}+k_{2}\left(s_{2}-s_{1}\right)+c_{2}\left(\dot{s_{2}}-\dot{s_{1}}\right)=0 \\
\quad \ddot{*} \cdot \vec{\cdot} \\
m_{1} \ddot{s_{1}}+k_{1}\left(s_{1}-s_{0}\right)+k_{2}\left(s_{1}-s_{2}\right)+c_{2}\left(\dot{s_{1}}-\dot{s_{2}}\right)=0
\end{array}\right.
$$

where $m_{1}$ is the mass of the wheel, namely, unspring mass; $m_{2}$ is the body mass, while $m_{3}$ stands for the mass of the motor; $k_{1}$ is the stiffness of the tire, while $k_{2}$ is the stiffness of vehicle suspension; $c_{2}$ stands for the damper factor of suspension; $s_{0}$ is road excitation; $s_{1}$ and $s_{2}$ are the displacement of suspension and body respectively.

For Fig. (3b), the equations are similar, just has an increase of $m_{1}$ in Eq. (1). Then use sine function as road excitation to carry out an analysis in frequency domain, the frequency of sine function will be added in step. The parameters are listed in Table $\mathbf{1}$ (values of parameters are similar as a car from Ford company), model will be simulated in Matlab/Simulink software. We can get the results like Figs. $(\mathbf{4}, \mathbf{5})$.

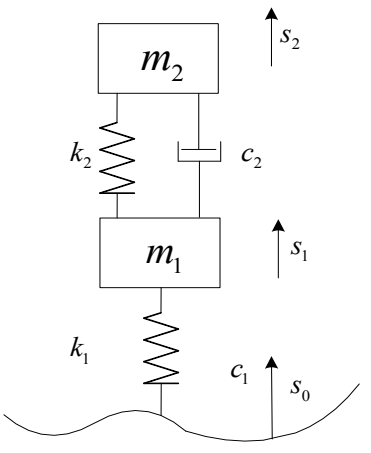

(a)

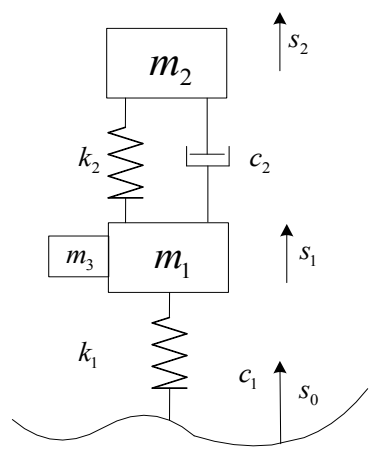

(b)
Fig. (3). Quarter car model for vibration analysis.

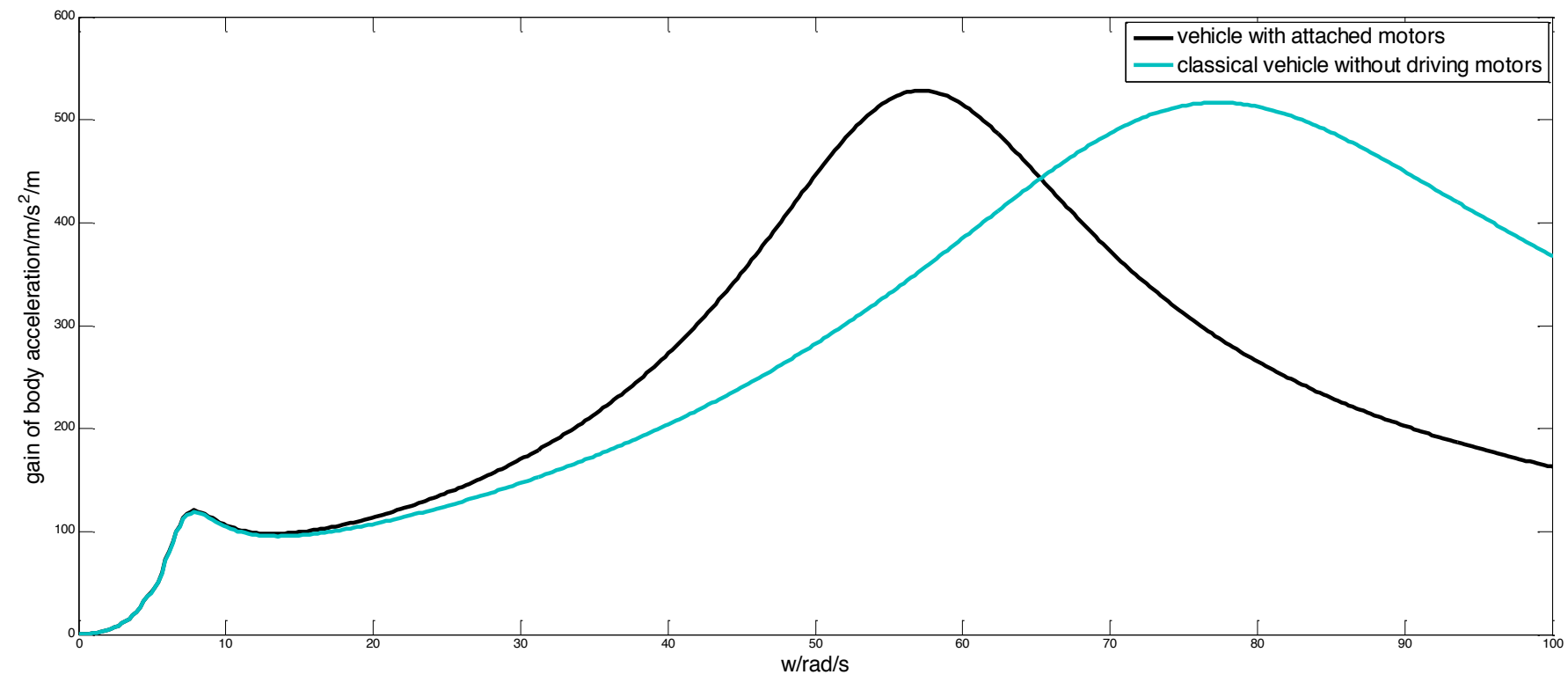

Fig. (4). Comparison on gain of body acceleration in frequency domain. 
Table 1. Parameters' value of quarter car model.

\begin{tabular}{|c|c|c|c|}
\hline Parameter & $\boldsymbol{m}_{\mathbf{1}} / \boldsymbol{k g}$ & $\boldsymbol{m}_{2} / \boldsymbol{k g}$ & $\boldsymbol{m}_{\mathbf{3}} / \boldsymbol{k g}$ \\
\hline \hline Value & 35 & 370 & 30 \\
\hline Parameter & $k_{1} / \mathrm{Nm}^{-1}$ & $k_{2} / \mathrm{Nm}^{-1}$ & $c_{2} / \mathrm{N} / \mathrm{ms}^{-1}$ \\
\hline Value & 200000 & 20000 & 1500 \\
\hline
\end{tabular}

As shown in Figs. $(4,5)$, compared to classical cars, owing to the mass of the attached motors, vehicles driven by in-wheel motors will maintain a larger wheel dynamic load, which will leads to a bad fluctuation of the tire contact force and, thus, may induce a terrible accident. Still, we can find the body acceleration of motorized vehicle is a little bigger than classical cars, which means that the ride performance of motorized vehicles is not as good as the classical one.

\section{A NOVEL LAYOUT SCHEME AND LQG CONTROL ANALYSIS}

\subsection{Layout Scheme to Reduce Unspring Mass}

In this section, a novel fix method is provided as Fig. (6) to solve the problems above [14]. As shown in the scheme, the driving motor is suspended by a damper and a spring on the driving axle of the vehicle, vehicles will driven by the motor through a pair of bevel gears. This kind of layout idea not only separates the motor from unspring mass, but also saves layout room in the vehicle. In addition, we may get a better performance if a good control method is provided. The simplified scheme is shown in Fig. (7). Where $s_{3}$ is the displacement of motor; $k_{3}$ is the spring mass, while $U$ is the active control force that generated by actuator; $m_{3}$ stands for the motor mass, other meanings of the parameters are the same as Table $\mathbf{1 .}$

Then vibration equations of Fig. (7) can be derived based on Newton law:

$$
\begin{aligned}
m_{2} \ddot{s_{2}}= & k_{2}\left(s_{1}-s_{2}\right)+c_{2}\left(\dot{\left.s_{1}-\dot{s_{2}}\right)}\right. \\
m_{1} \ddot{s_{1}}= & k_{1}\left(s_{0}-s_{1}\right)+k_{2}\left(s_{2}-s_{1}\right)+k_{3}\left(s_{3}-s_{1}\right) \\
& +c_{2}\left(\dot{\vec{s}}-\dot{s_{1}}\right)-U \\
\ddot{m_{3}} &
\end{aligned}
$$

\subsection{LQG Control Method of Suspended Motors}

Optimal method is a useful tool that is widely used to optimize the vehicles' performance [10-12]. The differential Equations above can be expressed as state-space form based on optimal LQG control theory:

$$
\begin{aligned}
& \dot{X}=A X+B U+F W \\
& Y=C X+D U
\end{aligned}
$$

where,

$X=\left[\begin{array}{cccccc} & \dot{S_{1}} & & \dot{S_{1}} & & \cdot \\ S_{1} & S_{2} & S_{2} & S_{3} & S_{3}\end{array}\right]^{T}$, is the state variables in the suspended motor system.

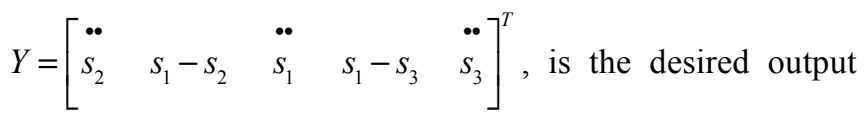
variables in the suspended motor system, the meanings of the variables in $Y$ can be described as body acceleration, dynamic deflection of suspension, wheel dynamic load, dynamic deflection of motor, motor acceleration respectively. The parameters of $Y$ can be regarded as evaluation standards, which can show whether a vehicle suspension systems are designed good or not. The value of

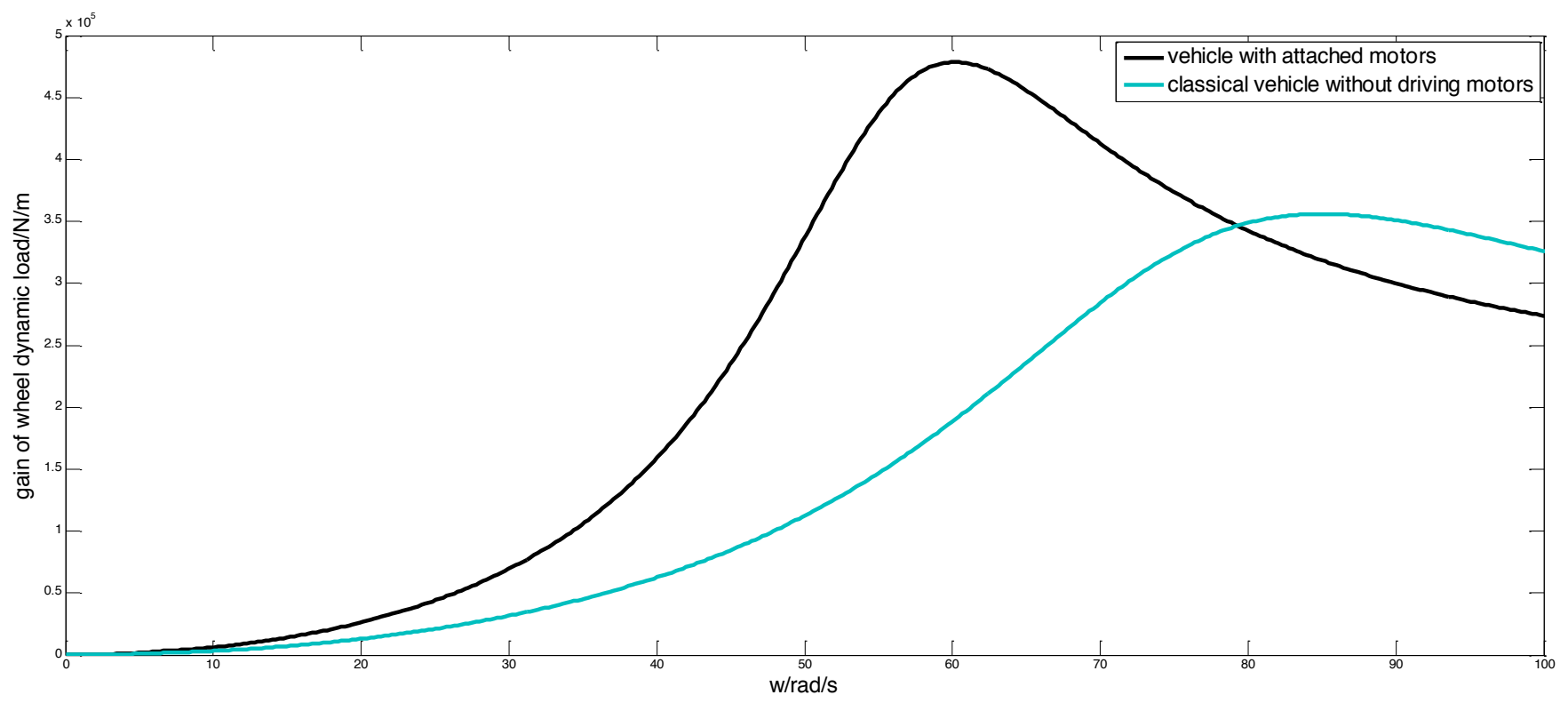

Fig. (5). Comparison on gain of wheel dynamic load in frequency domain. 
these parameters are the smaller, the better. $W$, which stands for the road input of the system, is equal to $S_{0}$. While other parameters that listed as follows can be obtained based on Eq. (2) Eq. (6).

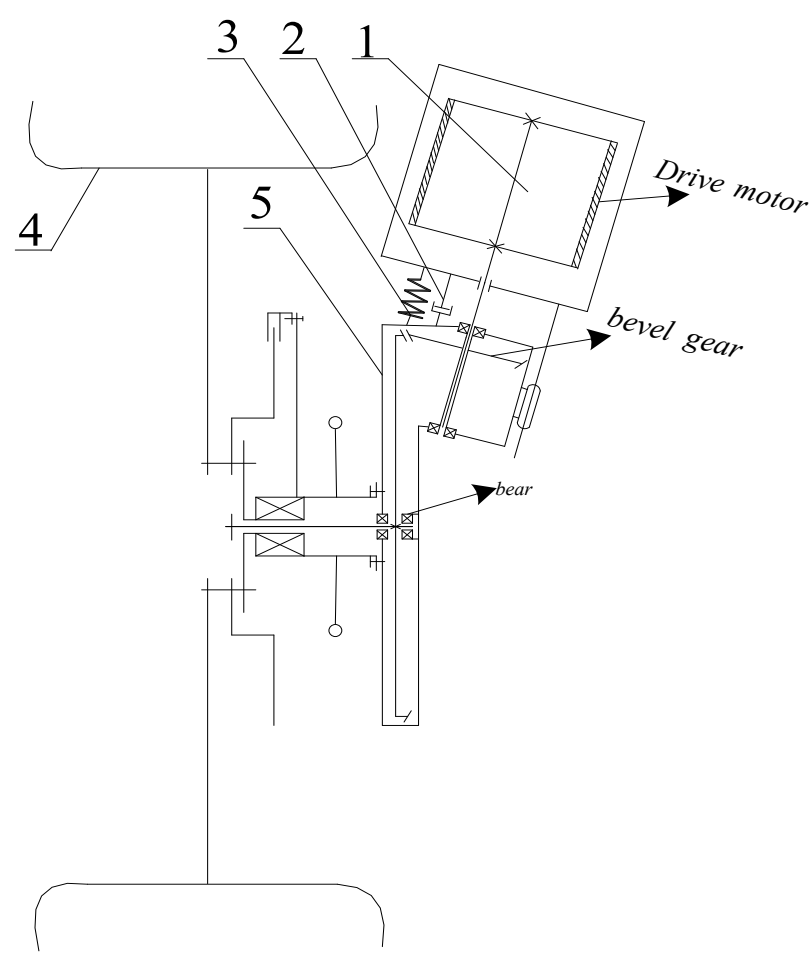

Fig. (6). Scheme of suspended motor.

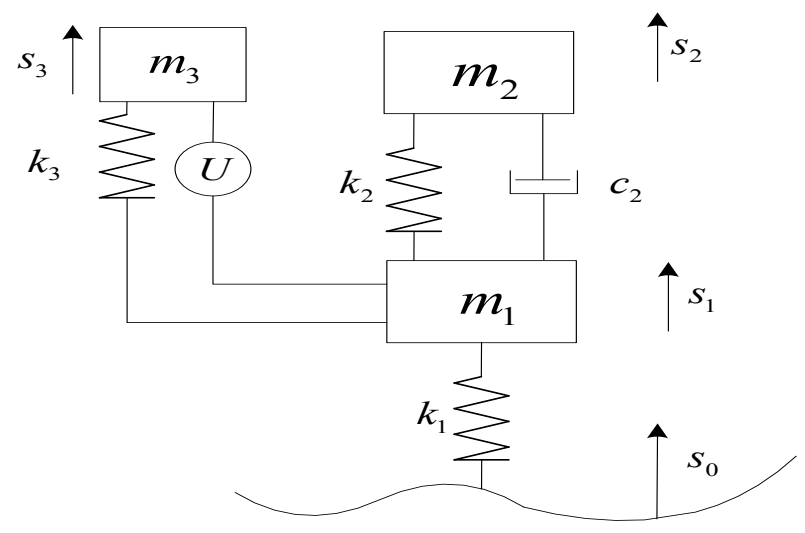

Fig. (7). Simplified model of Fig. (6).

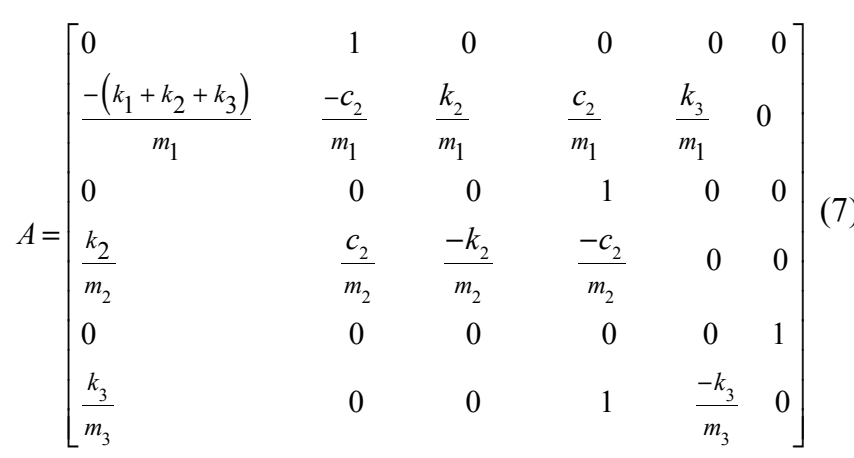

$B=\left[\begin{array}{llllll}0 & \frac{-1}{m_{1}} & 0 & 0 & 0 & \frac{1}{m_{3}}\end{array}\right]^{T}$

$C=\left[\begin{array}{lccccc}\frac{k_{2}}{m_{2}} & \frac{c_{2}}{m_{2}} & \frac{-k_{2}}{m_{2}} & \frac{-c_{2}}{m_{2}} & 0 & 0 \\ 1 & 0 & -1 & 0 & 0 & 0 \\ \frac{-\left(k_{1}+k_{2}+k_{3}\right)}{m_{1}} & \frac{-c_{2}}{m_{1}} & \frac{k_{2}}{m_{1}} & \frac{c_{2}}{m_{1}} & \frac{k_{3}}{m_{1}} & 0 \\ 1 & 0 & 0 & 0 & -1 & 0 \\ \frac{k_{3}}{m_{3}} & 0 & 0 & 1 & \frac{-k_{3}}{m_{3}} & 0\end{array}\right]$

$D=\left[\begin{array}{lllll}0 & 0 & \frac{-1}{m_{1}} & 0 & \frac{1}{m_{3}}\end{array}\right]^{T}$

$F=\left[\begin{array}{llllll}0 & \frac{k_{1}}{m_{1}} & 0 & 0 & 0 & 0\end{array}\right]^{T}$

The objective function of the system then can be expressed as following based on the optimal control theory [10]:

$J=\lim _{T \rightarrow \infty} \frac{1}{T} \int_{0}^{T}\left[\begin{array}{l}\ddot{\bullet}^{2} \\ q_{1} s_{2}+q_{2}\left(s_{1}-s_{2}\right)^{2}+q_{3} \dot{s}_{1}+ \\ q_{4}\left(s_{1}-s_{3}\right)^{2}+q_{5} \dot{s}_{3}^{2}\end{array}\right] d t$

Then Eq .(12) will be transformed to the Standard quadratic form, which can be deduced as:

$J=\lim _{T \rightarrow \infty} \frac{1}{T} \int_{0}^{T}\left(X^{T} Q X+U^{T} R U+2 X^{T} N U\right) d t$

where, $\mathrm{Q}$ is the weighting matrix of state variable, $\mathrm{R}$ is the weighting matrix of control force, $\mathrm{N}$ is weighting factor of cross variables. The value of these parameters can be obtained by the following equations:

$Q=C^{T} Q_{0} C$

$R=D^{T} Q_{0} D$

$N=C^{T} Q_{0} D$

In which,

$$
Q_{0}=\left[\begin{array}{ccccc}
q_{1} & 0 & 0 & 0 & 0 \\
0 & q_{2} & 0 & 0 & 0 \\
0 & 0 & q_{3} & 0 & 0 \\
0 & 0 & 0 & q_{4} & 0 \\
0 & 0 & 0 & 0 & q_{5}
\end{array}\right] .
$$

Then, a command in matlab software will be used to get the feedback gain matrix $\mathrm{K}$ :

$(K, S, E)=\operatorname{lqr}(A, B, Q, R, N)$

where, $S$ stands for the solution of Riccati equation, while $E$ is the eigenvalue of the system. Then the control force desired can be deduced as: 
$U=-K X$

With different weighing factors of $q$ i, one can get different control force.

\section{SIMULATION RESULTS AND ANALYSIS}

The simulation tests will be carried out under Matlab/Simulink circumstance. First and foremost, the results generated from frequency domain analysis will be compared. Finally, the work will be taken in time domain, in which a general road model will be introduced. The value of weighing factors in this article can be seen in Table 2 .

Table 2. Values of weighing factor.

\begin{tabular}{|c|c|}
\hline Weighing Factor & Value \\
\hline \hline $\mathrm{q}_{1}$ & $5 \mathrm{e} 11$ \\
\hline $\mathrm{q}_{2}$ & $3 \mathrm{e} 4$ \\
\hline $\mathrm{q}_{3}$ & 10 \\
\hline $\mathrm{q}_{4}$ & $3 \mathrm{e}-13$ \\
\hline $\mathrm{q}_{5}$ & $15 \mathrm{e} 9$ \\
\hline
\end{tabular}

\subsection{Frequency Analysis}

Analysis in the frequency domain can illustrate the performances of a system in all kinds of working conditions [9]. In the frequency domain, working conditions of vehicles are always under $15 \mathrm{hz}$ generally, which is equal to 100 $\mathrm{rad} / \mathrm{s}$. Then the results can be showed as Figs. (8-10).

Seen from Figs. (8-10). The main parameters, namely, the body acceleration, wheel dynamic load as well as the dynamic deflection under LQG controller are smaller than that of the unsuspended motorized vehicle. Specifically, the reduce of wheel dynamic load is very large, which means that the one under control with motors suspended performed very well in safety property. In addition, the ride performance of the one under control also better than the one unsuspended.

\subsection{Analysis in Time Domain}

A random road with B level will be built as a extinction which can simulate real work conditions [13]. In general, methods for building a random road surface input can be known as linear filtering method and harmonic superposition method. Here we use the previous one thanks to its simplicity and accuracy. The main idea of this way is to get values obtained filter by calculating and processing the power spectrum on the road, after which the computergenerated normal random number road waveform is obtained by the filter. The equation is as follows:

$\dot{s_{0}}(t)=-2 \pi f_{0} s_{0}(t)+2 \pi \sqrt{G_{q}\left(n_{0}\right) u} w(t)$

$S_{0}(t)$ is equal to $\mathrm{W}$ in the state-space form as Eq. (5), where, $f_{0}=0.0628 \mathrm{~Hz}$ stands for offline cutoff frequency, $S_{0}(t)$ is the road input value, $w(t)$ can be replaced by a white noise whose intensity is $1, u$ is vehicle speed, $G_{q}\left(n_{0}\right)$ is road roughness coefficient, which is a constant decided by road conditions. For road of B level, $G_{q}\left(n_{0}\right)=64 \times 10^{-6} \mathrm{~m}^{3}$. The road input at $60 \mathrm{~km} / \mathrm{h}$ is shown in Fig. (11).

The results analysis of time domain can be listed as:

Figs. $(12,14,16)$ are the comparison of judgment parameters, while Figs. $(\mathbf{1 3}, \mathbf{1 5}, \mathbf{1 7})$ are the spectrum density analysis of the parameters under B level road respectively. With the LQG controller, one can find that not only the wheel dynamic load was sharply reduced, but also the body acceleration has a reasonable decrease. The dynamic deflection of suspension systems has a very small drop. It is evident that one can come to a conclusion that the motor suspended one always enjoy better properties in safety and ride than the one unsuspended without control.

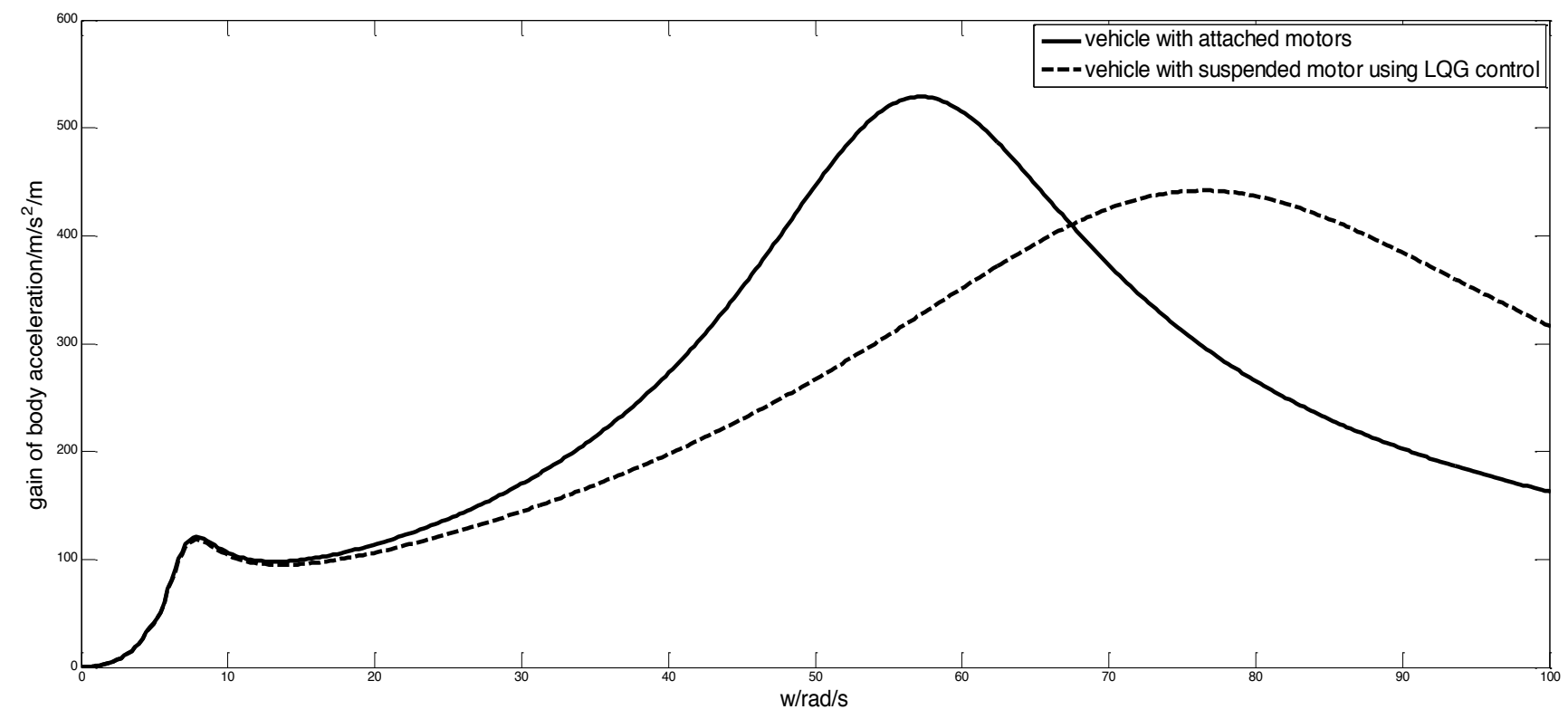

Fig. (8). Gain of body acceleration. 


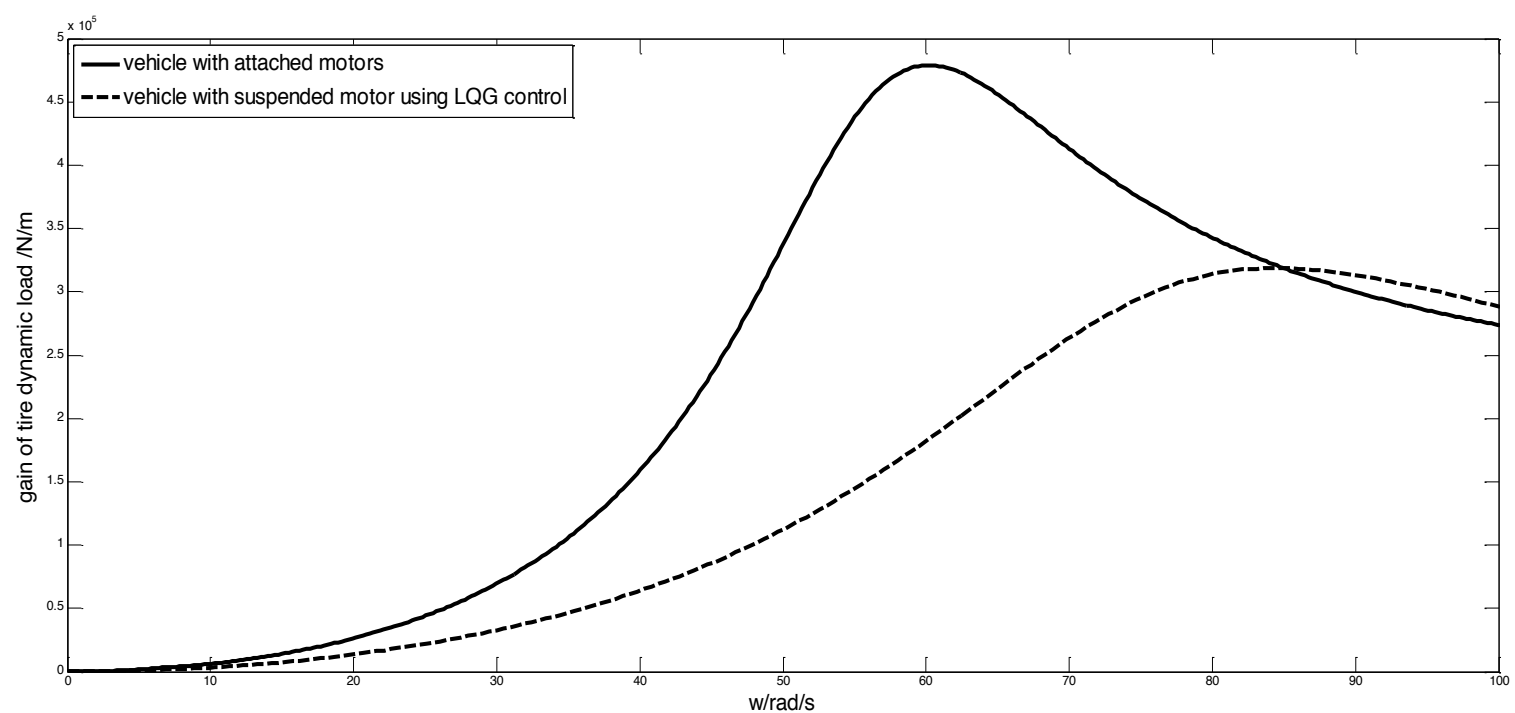

Fig. (9). Gain of wheel dynamic load.

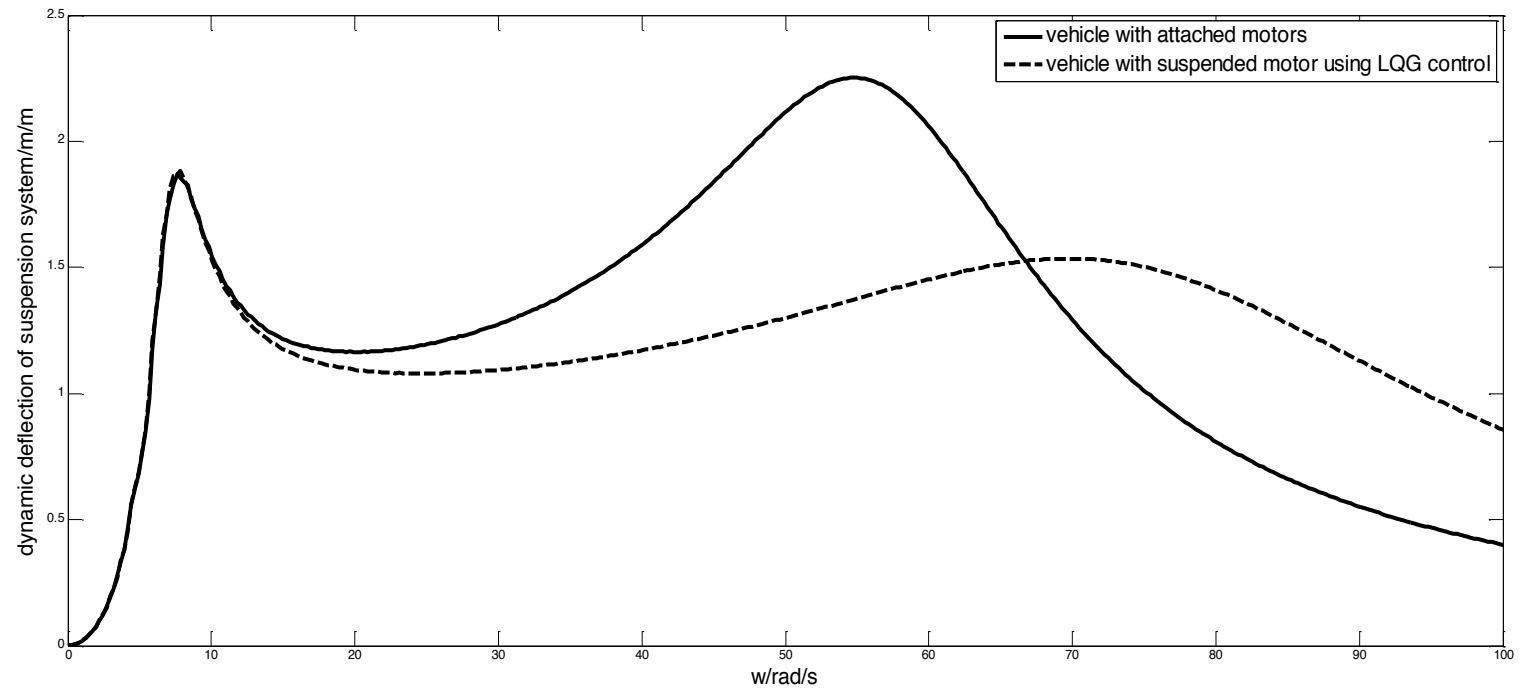

Fig. (10). Gain of dynamic deflection of suspension system.

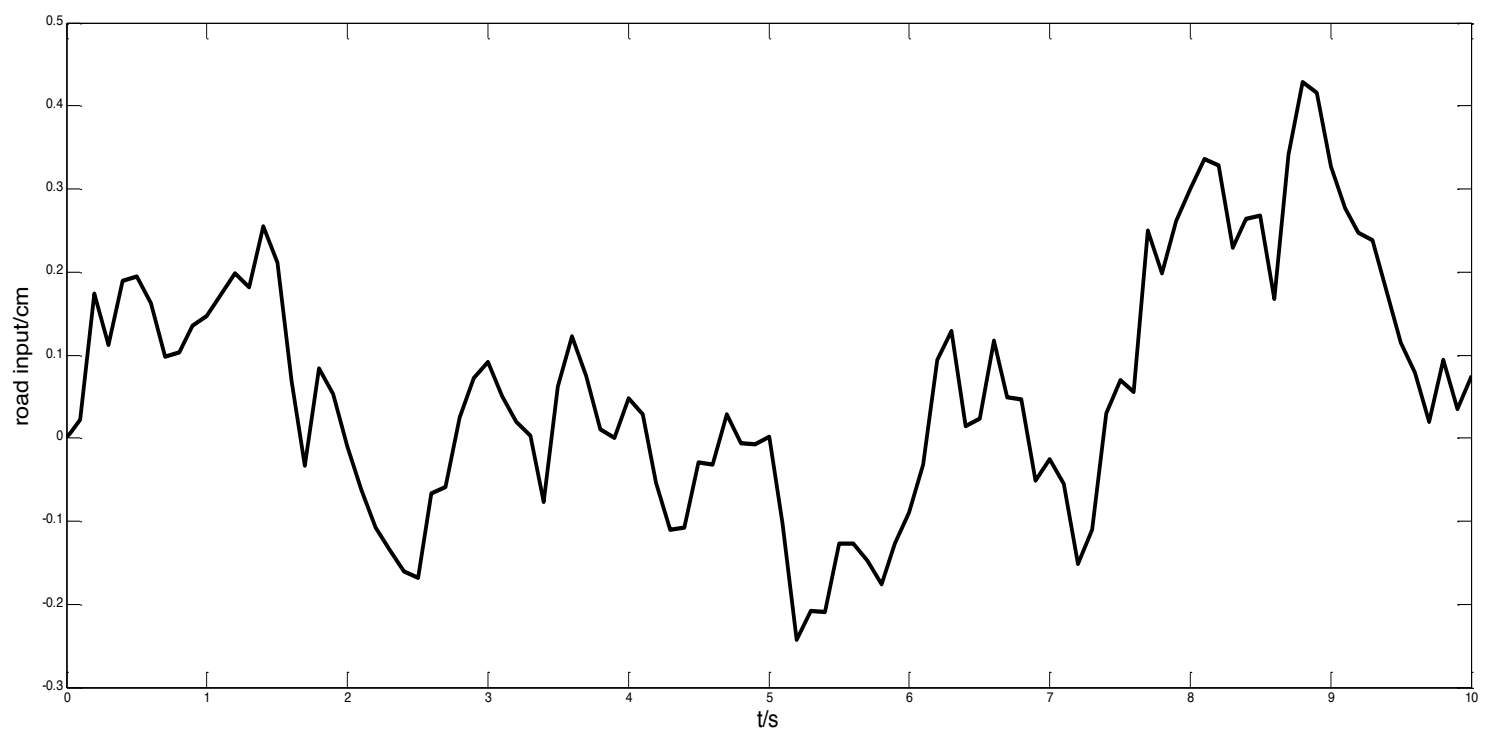

Fig. (11). Road excitation with $60 \mathrm{~km} / \mathrm{h}$. 


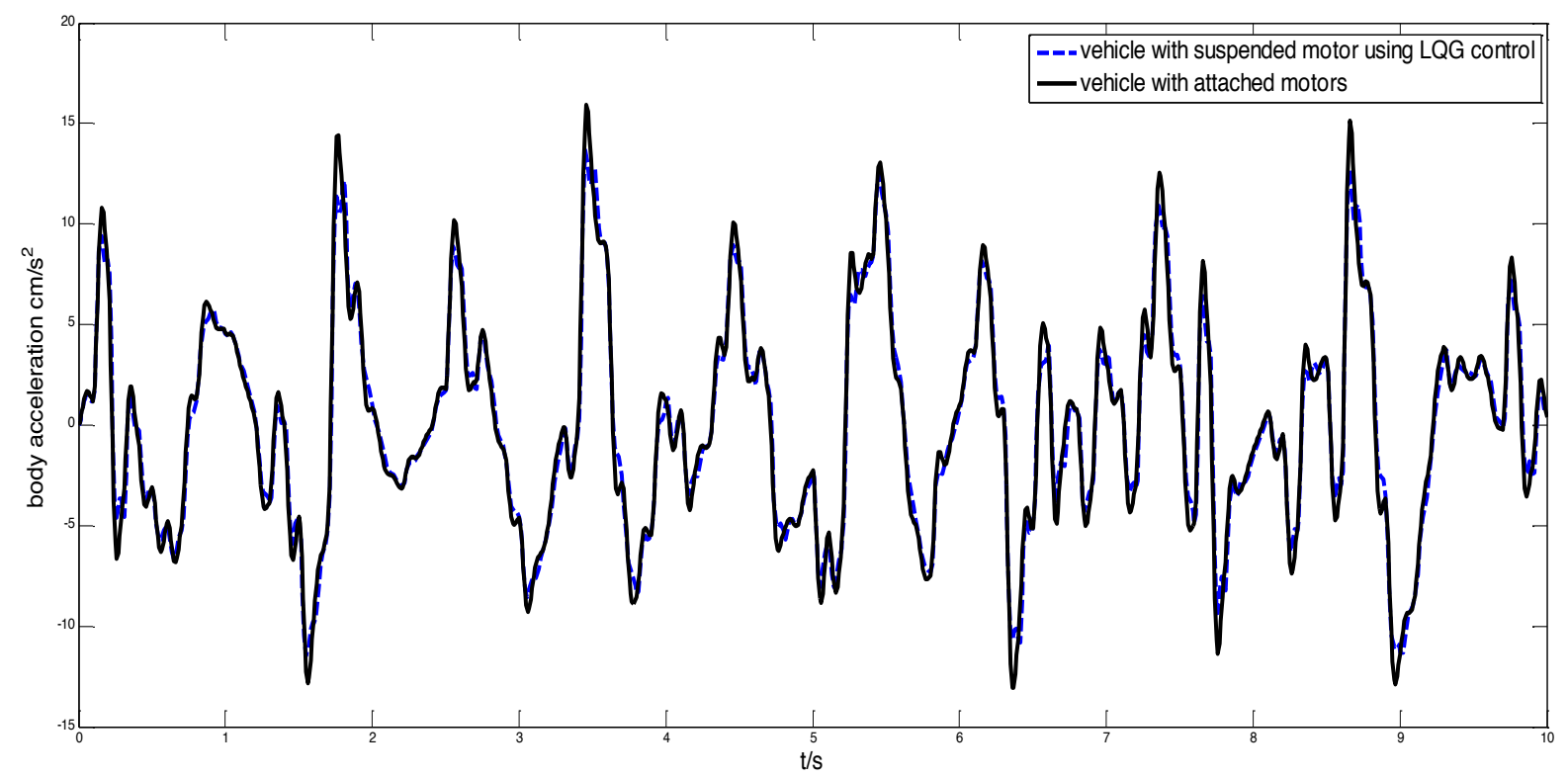

Fig. (12). Comparison of body acceleration.

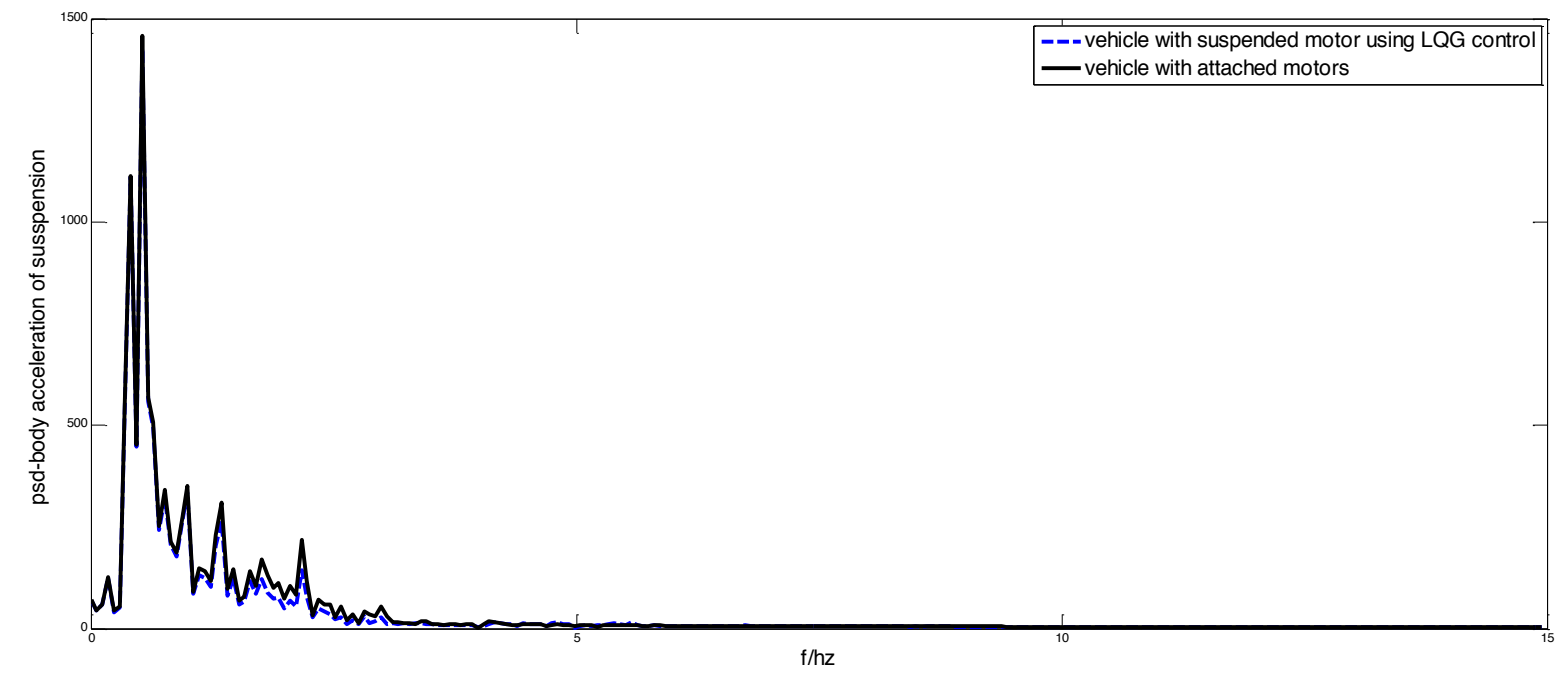

Fig. (13). Comparison of PSD curve on body acceleration.

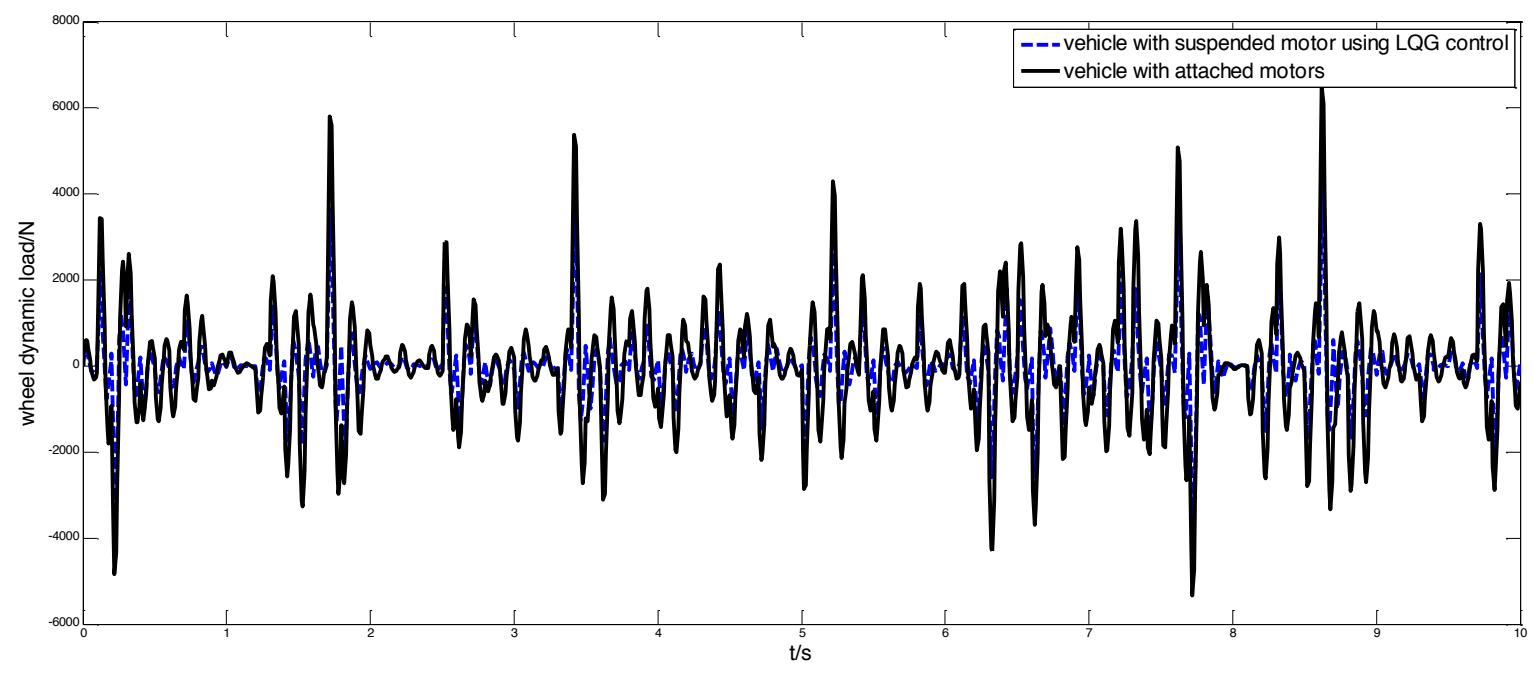

Fig. (14). Comparison of wheel dynamic load. 


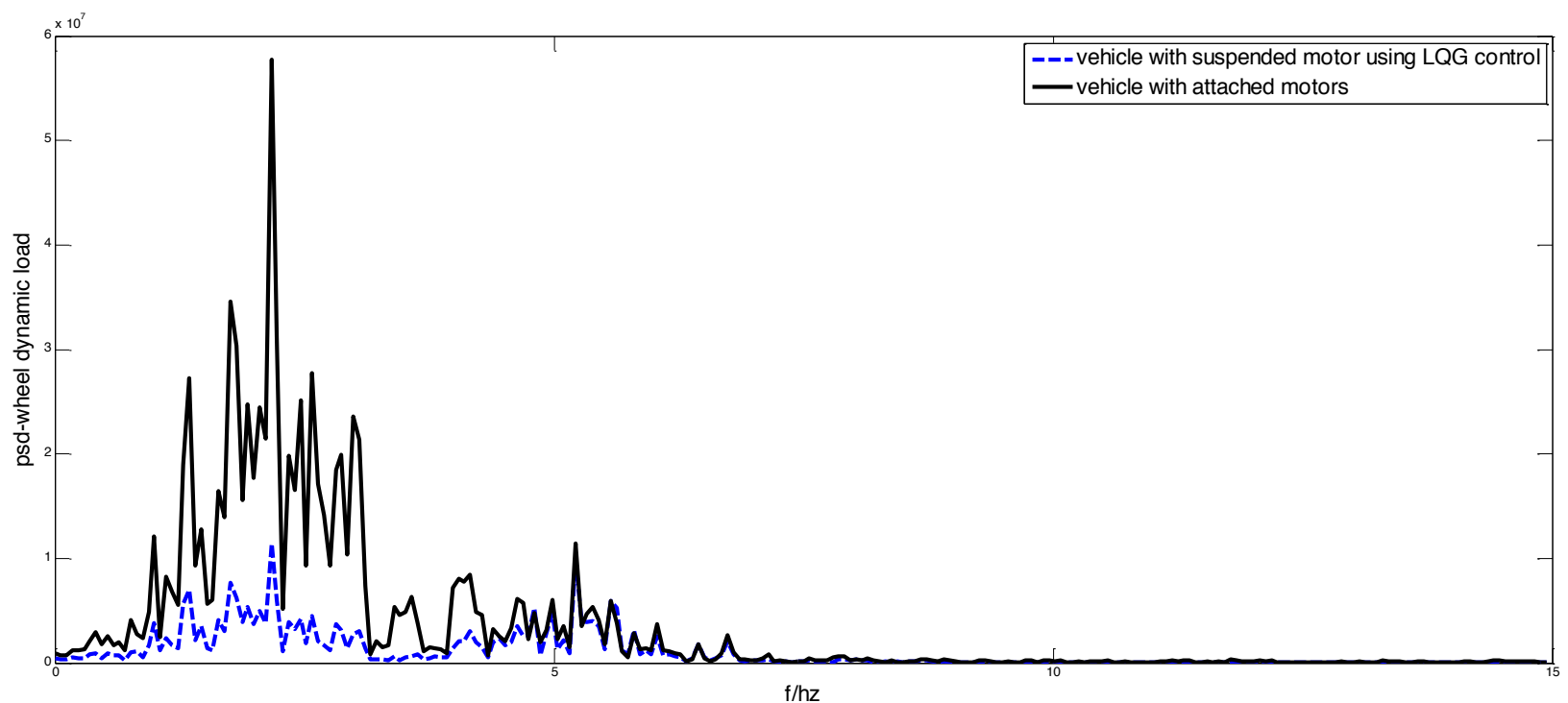

Fig. (15). Comparison of PSD curve on wheel dynamic load.

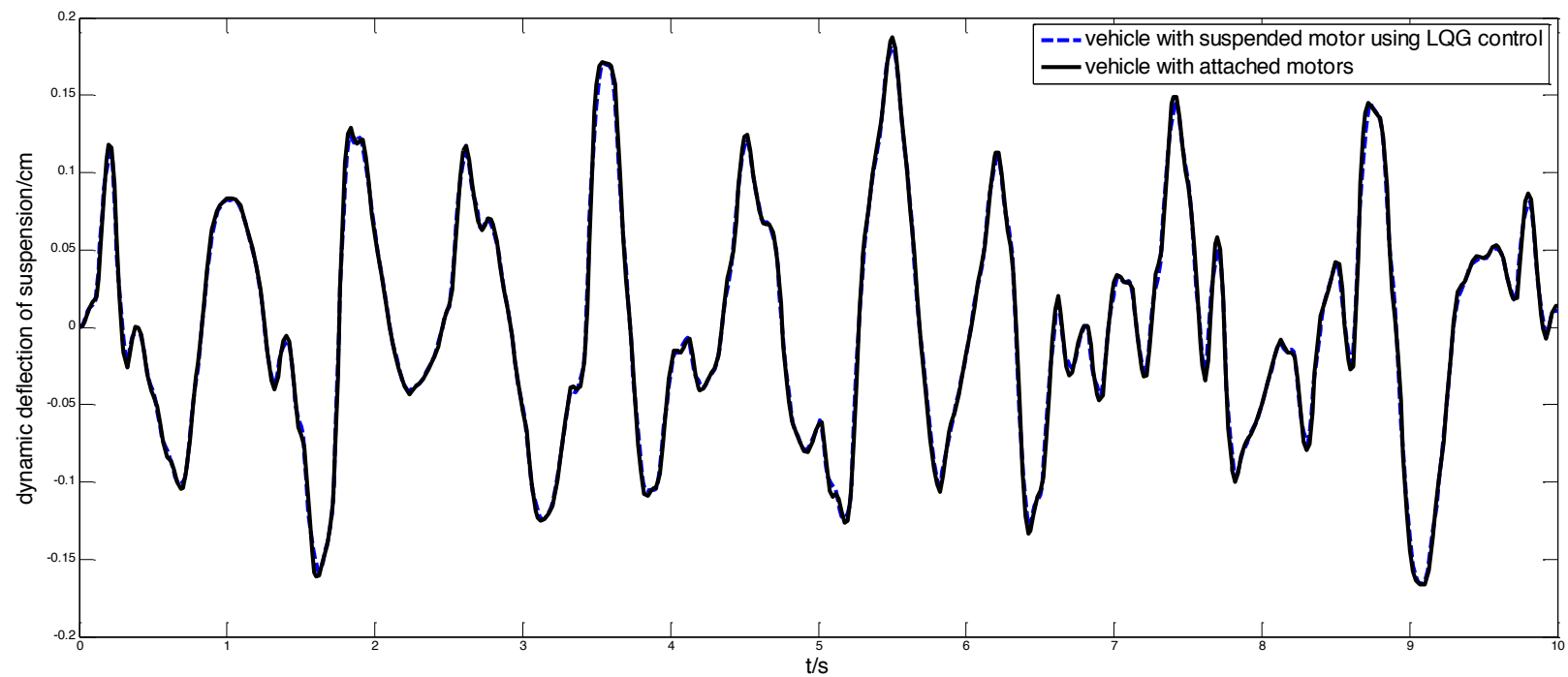

Fig. (16). Comparison of dynamic deflection.

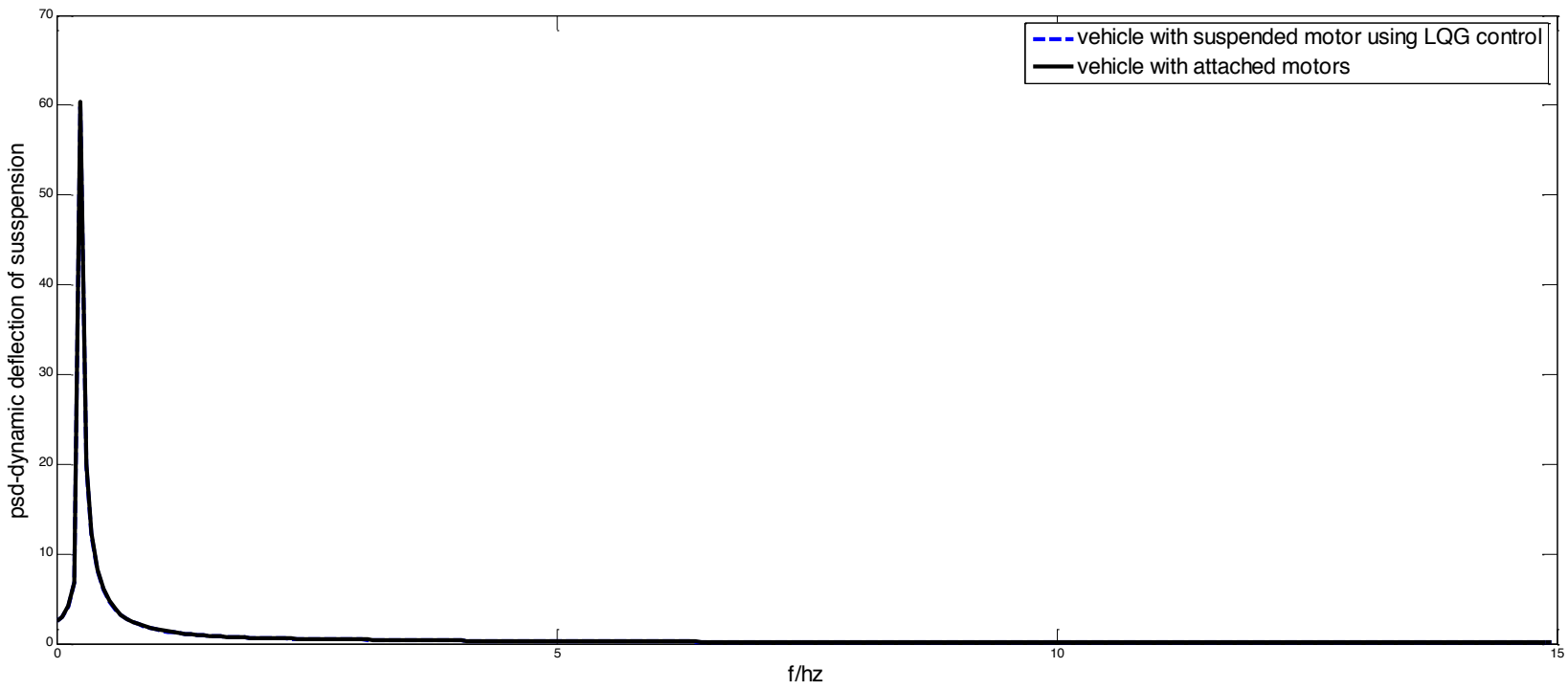

Fig. (17). Comparison of PSD curve on dynamic deflection. 


\section{CONCLUSION}

To sum up, structure of vehicles driven by attached motors is described, then the merits and drawbacks of this drive method are listed. As shown in Figs. $(4,5)$, the ride and safety properties are deteriorate, although the motorized electric vehicle has a compact structure. To solve the increase of unspring mass of attached motors, an idea that make the motor suspended is provided as Fig. (6), after which a optimal LQG control law is proposed on the suspended motors. By the comparisons both in time domain and frequency domain, shown in Figs. (8-17), it is evident that the value of body acceleration in vehicles with suspended motors is smaller than the motor attached structure; the wheel dynamic load in the suspended one is also smaller. From the discussion above, we can easily come to a conclusion that vehicles driven by suspended motors armed with LQG active controller not only make vehicle structure simple, but also can be taken as an absorber in reducing body acceleration and improving tire attach force. The usage of this structure is good for enhancing ride and safety properties of electric vehicles driven by in-wheel motors, which will have practical values in the future.

\section{CONFLICT OF INTERESTS}

The authors declare that there is no conflict of interests regarding the publication of this paper.

\section{ACKNOWLEDGEMENTS}

This work is supported by the Postdoctoral Fund (No. 801130110415) and the Horizontal Projects (No. 2012220101001314).

\section{REFERENCES}

[1] P.C. Cho, W. Wylam, and D. Crecelius, "Advanced hybrid electric vehicle propulsion systems with individual wheel brushless traction motors", SAE 2000-01-3110, 2000, doi: 10.4271/2000-01-3110.
[2] S.-K. Chung, H.-S. Kim, C.-G. Kim, and M.-J. Youn, "A new instantaneous torque control of PM synchronous motor for HighPerformance Direct-Drive applications", IEEE Transactions on Power Electronics, vol. 13, pp. 388-400, 1998.

[3] M. Terashima, and Mizuno, "Novel motors and controllers for high-performance electric vehicle with four in-wheel motors". IEEE Transactions on Industrial Electronics, vol. 44, pp. 28-38, 1997.

[4] G. Freitag, M. Klopzig, K. Schleicher, M. Wilke, and M. Schramm, "High-performance and highly efficient electric wheel hub drive in automotive design", Electric Drives Production Conference (EDPC), 2013, $3^{\text {rd }}$ International IEEE Conference Publications, 2013, pp. 1-7.

[5] A. Dadashnialehi, A. Bab-Hadiashar, Z. Cao, and A. Kapoor, "Intelligent sensorless ABS for in-wheel electric vehicles", IEEE Transactions on Industrial Electronics, vol. 61, pp. 1957-1969, 2014.

[6] G. Le Solliec, A. Chasse, J. Van-Frank, and D. Walser, "Dual mode vehicle with in-wheel motor regenerative braking optimization", Oil \& Gas Science and Technology - Rev. IFP Energies nouvelles, vol. 68, pp. 95-108, 2013.

[7] J. Wang, Q. Wang, L. Jin, and C. Song, "Independent wheel torque control of 4WD electric vehicle for differential drive assisted steering", Mechatronics, vol. 21, pp. 63-76, 2011.

[8] Y. Hori, "Future vehicle driven by electricity and controlResearch on four-wheel-motored, UOT electric march II", IEEE Transactions on Industrial Electronics, vol. 51, pp. 954-962, 2004.

[9] L-Q Jin, C-X Song, and Q-N Wang, "Evaluation of influence of motorized wheels on contact force and comfort for electric vehicle", Journal of Computers, vol. 6, pp. 497-505, 2011.

[10] L. Bo, and Y. Fan, "The design of LQG controller of active suspension", Journal of System Simulation, vol. 15, 2003.

[11] Z. Zheng, and X. Wang, "Research on Neural Network PID quadratic optimal controller in active magnetic levitation", The Open Mechanical Engineering Journal, vol. 8, pp. 42-47, 2014.

[12] R. Singh, P. K. Mandal, A. K. Singh, R. Kumar, and A. Sinha, "Optimal underground extraction of coal at shallow cover beneath surface=Subsurface Objects: Indian Practices", Rock Mechanics and Rock Engineering, vol. 41, pp. 421-444, 2008.

[13] J. LiQiang, and L. Yue, "Study on Self-tuning control strategy of suspension systems for improving vehicle ride performance", International Journal of Control and Automation, vol.7, pp.129142, 2014.

[14] Y. Liu, and L. Jin, "A method for enhancing ride and safety properties of vehicles driven by in-wheel motors", International Journal of Modelling and Simulation, vol. 34, pp. 1-6. 2014. 